\title{
Recognizing and Anticipating Stress Related Complacent Behavior in the Manufacturing Industries
}

\author{
Ricardo Alberto Pineda \\ Walden University \\ Teresa Lao \\ Colorado State University Global
}

Numerous safety studies suggest that stress complacency related accidents in manufacturing industries continue to cause injuries or fatalities because of the absence of emotional resources for leaders, who are unable to prevent accidents when these conditions exist. Leaders of the manufactory industries may not have the appropriate emotional measures which are significant to recognize employees' underlying complacent behavior. The purpose of this quantitative correlational study was to evaluate the relationship between leaders' emotional intelligence resources and their ability to recognize stressful employees thus, prevent injuries and fatalities in the workplace. The research questions address key traits of emotional intelligence regarding emotional perceptions and control which are needed to make the leaders more effective at recognizing and responding to stress complacency related incidents. Specifically, this study includes a method of inquiry in the form of a survey designed to measure 140 leaders' emotional intelligence competencies in 3 Western Virginia food and beverage manufactories. Structural equation modeling was used to determine the multivariate relationships among leaders' skills and safety prevention. Leaders' emotional intelligence results indicated a negative effect on stress identification in either upper or middle leadership groups preventing them from exercising safe prevention error with their employees. Promoting leaders' emotional intelligence engagement may potentially contribute to social change helping the food and beverage organizations to protect their employees from getting hurt, promoting strong safety cultures, maintaining a positive impact on families and workers and thereby, increasing community resilience.

Keywords: Manufacturing Industry, Stress, Homeostatic, Relationship Management, Performance Plateau, Emotional Intelligence, Primal Leadership, Structural Equation Model, Cultural Intelligence

\section{INTRODUCTION}

Globalization, technology, and skilled labor competition continue to increase the speed by which manufacturing industries currently operate (Khan \& Bashar, 2016). New technology allows corporations to achieve greater efficiencies and under lean manufactory rules, employees have zero error tolerance while attaining peak performances during their work (Hallett and Hoffman, 2014; Kumar, Dhingra, \& Singh, 2017). Although significant safety training is mandated by federal regulators to prevent major 
accidents, numerous injuries are caused by employees under implicit stress as they become complacent while doing tedious work (Arstad \& Aven, 2017). Current records indicate that accidents due to human errors are responsible for many occupational injuries in the workplace (United States Department of Labor, 2015). These findings underscore the need for increased research on leaders' responsibility to identify and prevent anxiety-ridden employees from taking unnecessary risks that cause harm (Strutton \& Tran, 2014). The core of this quantitative study consisted in the analysis of several leaders' emotional resources, which influenced their safety performance and help them perceive employees' underlying emotions under job stress (Lu \& Kuo, 2016). Prior research has been conducted on the effects of job stress. Previous researchers identified relationships between job-related stress, emotional intelligence, and safety behavior; however, this research did not consider the leaders' emotional traits and their selfinitiative competencies needed to take control of a safety situation when employees' complacent stress is present (Lu \& Kuo, 2016). In this study, the researcher narrowed this literature gap by adding an in-depth review of the links between self-efficacy and management competencies in the prevention of workplace injuries in a manufactory environment to the canon of work on leadership. This study helped explain the reasons why leaders in the manufacturing industry emotional unbalance continue to experience safety incidents caused by employees' underlying stress while performing their daily tasks. Although anxiety is a natural response to stress, it represents a hazard to employees who work under this emotional and physical strain (Strutton \& Tran, 2014). This quantitative correlational study may promote a leader's deep involvement in the prevention of employees' safety errors by helping them develop a sense of emotionality and perception needed to prevent employees' safety errors. Therefore, the researcher described the literature gaps related to the background of the study found in prior research and theories, introduced the problem statement made to described the intent of the study, discussed the independent and dependent variables, introduced a theoretical and conceptual models to provide the assumptions, explored the limitations and the significance of the study, offering a summary of these components and concluding by recommending options to improve the leaders' competencies to prevent safety errors that may end up in fatalities.

\section{THE PROBLEM}

Despite significant safety controls mandated by federal regulators to prevent major accidents in manufactories, numerous injury accidents and fatalities show that control is still not sufficient in many cases (Adhikari, 2015). Accidents that result from human errors are responsible for many occupational injuries in all workplaces as reported by the Federal Government. Department of Labor safety records indicated that fatalities in workplaces average 12 per day, or 4,380 deaths per year (United States Department of Labor, 2015). New technologies allow corporations to achieve greater efficiencies and under lean manufactory rules, employees have zero error tolerance when working their equipment (Kumar et al., 2017). Maintaining a strong competitive edge in the marketplace demands that employees attain peak performance while executing their tasks safely (Hallett \& Hoffman, 2014).

Employees' stress caused by family problems impact their job performance and cannot be ignored since it is part of their life (Ismail et al., 2013). Identifying individuals under family stress, a critical factor that impacts behavior and puts human safety in jeopardy, is not easily recognized, especially when employees' emotions are not manifested out of fear of recrimination or losing their jobs (Nohe, Meier, Sonntag, \& Michel, 2015). Underlying individual stressors of employees in the food and beverage manufactory industry play a contributing role in recordable accidents and fatalities (Adhikari, 2015). The general problem is that employees' adoption of an attitude of complacency due to unforeseeable role stressors in the food and beverage manufactories labor force continues to be one of the main reasons for accidental injuries in workplaces (Adhikari, 2015). The specific problem is that leaders of the food and beverage manufactory may not have the proper emotional intelligence traits to recognize employees' underlying complacent stress behavior (Goleman et al., 2013). Miao, Humphrey, and Qian (2016) recommended the importance for leaders to have these emotional intelligence traits in place so that they 
become proficient in displaying their emotions, invoking emotions in others, and conveying a message of authenticity to their followers.

\section{PURPOSE OF THE STUDY}

The purpose of this quantitative correlational study was to examine if leaders of the food and beverage manufactories have the proper emotional intelligence competencies that help recognize employees' underlying complacent stress behavior (Goleman et al., 2013). The study examined and explained the influence of leadership competency variables, as recommended by Jacob (2013). This study assisted with the development of two structural equation models (SEM) to test the groups' power of leadership self-mastery skills (Hamzah, Othman, Rashid, Besir, \& Hashim, 2012). These proposed models will help leaders develop an effective mindset when making decisions to prevent implicit complacent behavior due to stress (Hamzah et al., 2012; Naderpour, Lu, \& Zhang, 2014). The independent variables will be the emotional leadership competencies that manipulate the leadership's outcomes while the dependent variable will be the latent emotional categories that guide the behavioral leadership skills. Leaders who apply emotional intelligence are powerful in showing their emotions, bringing out emotions in others, communicating truthfully in all they do, and impacting their employees' trust. Thus, contributing to the development of healthy and safe workplaces in the food and beverage manufactories may impact social changes in the industrial communities. The questions and hypothesis that led to this study were:

1. Question 1: Do food and beverage manufactory leaders have the proper emotional intelligence traits to recognize employees' underlying complacent stress behavior?

1.1. $H_{0} 1$ : Food and beverage manufactory leaders do not have the proper emotional intelligence traits to recognize employee's underlying complacent stress behavior.

1.2. $H_{a} 1$ : Food and beverage manufactory leaders have the proper emotional intelligence traits to recognize employee's underlying complacent stress behavior.

2. Question 2: Do food and beverage manufactory leaders execute emotional perceptions and controls to prevent employees' underlying complacent stress behavior?

2.1. $H_{0} 2$ : Food and beverage manufactory leaders do not execute emotional perceptions and control to prevent employees' underlying complacent stress behavior.

2.2. $H_{a}$ 2: Food and beverage manufactory leaders execute emotional perceptions and control to prevent employees' underlying complacent stress behavior.

\section{METHODOLOGY}

\section{Context of the Study}

Methodology in research studies constitutes the systematic analysis of principles and techniques used in a discipline of study (Arthur Jr. et al., 2014). In general, the methodology is a research strategy that establishes the methods used in the study (Hamm et al., 2013). In this study, a quantitative method of study to analyze the leaders' emotional resources which influence their safety performance and help them perceive employees' underlying emotions under job stress was achieved (Lu \& Kuo, 2016).

\section{Epistemological Framework}

Three theories served as the foundation for this study. Transformational leadership (TL) theory by James V. Downton, primal leadership theory (PL) by Goleman et al. (2013) and Vroom expectancy theory of motivation by Victor H. Vroom (1964). These theories described the critical leadership emotional resources that open the doors of communication between leaders and followers (McCleskey, 2014). The overlay of TL theory and emotional intelligence traits help frame the food and beverage manufactory leaders' components that influence the employees' performance (Jadhav \& Gupta, 2014; Malos, 2012; Mathew \& Gupta, 2015; Petrides, 2017). The TL theory aids leaders in recognizing a broad range of emotional signals and letting them sense the felt but unspoken emotions in a person or a group 
(Goleman et al., 2013; Petrides, 2017; Sunindijo \& Zou, 2013). Petrides' (2017) trait emotional intelligence (EI) constructs and trait emotional intelligence survey tool helped to test the hypotheses that emotional intelligence traits have moderating effects in transformational leaders and mitigate the negative effects of job stressors on employees. Petrides suggested the constructs that will be used to frame the independent variables of emotional intelligence. PL theory by Goleman et al. (2013) will be the foundation for the food and beverage manufactory leaders to create a positive environment that will impact their followers' behavior. The PL theory will aid the food and beverage manufactory leaders to lead with emotional intelligence, not just to gain positive results, but to establish deep emotional connections with others and to bring out the best in their people (Ackley, 2016; Goleman et al., 2013). The application of this theory help employees brings forth their problems that cause their stress inside or outside the workplace (Newton, Teo, Pick, Ho, \& Thomas, 2015; Yang, Rosenblau, Keifer, \& Pelphrey, 2015).

The Vroom expectancy theory of motivation was used to frame the dependent variables of selfmastery development, which helps leaders recognize employees under fatigue, complacency, or anxiety. This theory tested the leaders' ethical standards and expected to choose safety first in all they do despite corporate attainments needs (Ernst, 2014; Lazaroius, 2015; Parijat \& Bagga, 2014). This previously applied theory aligned current transformational leadership skills (Mathew \& Gupta 2015) with emotional intelligence traits and learned abilities (Goleman et al., 2013; Petrides, 2017) which lead to the investigation of leadership groups levels of emotion (Adhikari, 2015; Joost, 2013).

The approach and theories of this study related to the research questions and their hypotheses, as they explained and tested the principles that describe leaders' quality attributes that would prevent accidents from continuing (Goleman et al., 2013; Parijat \& Bagga, 2014; Petrides, 2017). These theories deepen our understanding of the motivational mechanisms involved in the relationship between leaders and followers (Eberly, Johnson, Hernandez, \& Avolio, 2013), thus, obtaining a leaders' optimal prevention resources to avoid accidents in the workplace (Lu \& Kuo, 2016). Figure 1 represents the theoretical, study conceptual framework model. The model accounts for a cross-sectional analysis that seeks leaders' emotional resources to mitigate employees' stress in the workplace.

FIGURE 1

THEORETICAL CONCEPTUAL FRAMEWORK

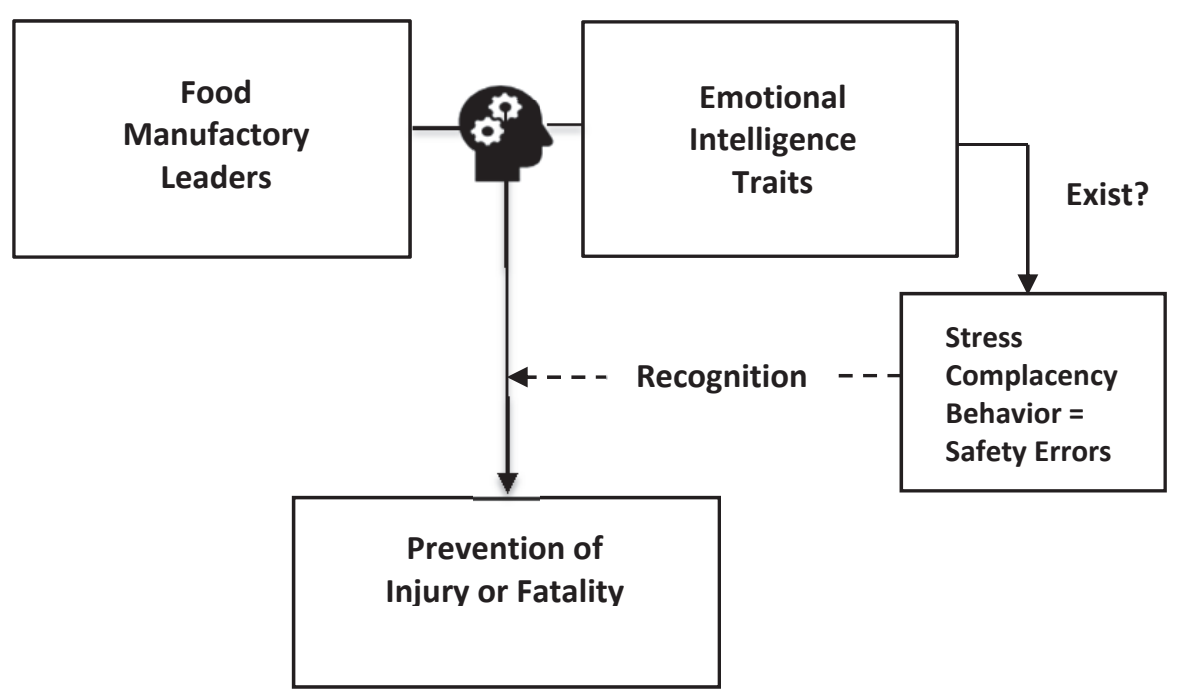




\section{Data Creation}

The data was planned from a population consisted of 140 leaders from the food and beverage manufactory industry. The food and beverage manufactory industry divide their leadership groups as follows: the upper leadership group and the middle leadership group. The upper leadership group consisted of vice-presidents, plant managers, operations managers, maintenance managers, quality managers, financial managers, warehouse managers, and human resources managers. The middle leadership group consisted of department unit leaders, shift unit leaders, floor supervisors, maintenance supervisors, quality supervisors, and utilities and grounds supervisors. The sample was made up of approximately 140 leaders from three food and beverage manufactories in the Shenandoah Valley region of western Virginia in the United States. The data collection lasted ten days. The total amount of selected respondents was scheduled to be approximately 140. However, during the recruitment process, a major setback occurred. One of the companies declined participation in the survey. Their reasoning for withdrawing from the survey was because they entered a hyper-care process status. Hyper-care occurs when manufactories have low-performance issues, and they need time to focus on their equipment reliability and operational performance. Two additional companies were invited to participate in the survey. The first company had no legal approval while the second declined based on their ability to provide approval from top executives on time to participate. With 70 available participants and based on the results from Wolf et al. (2013) Monte Carlo study, size rules and calculations were made. The study surveying continued by selecting the recommended 10 cases per variable leading to a sample size from 40 to 240 participants.

\section{Limitations}

Limitations are incidents that are out of the researcher's control, and they are potential weaknesses for any study (Simon \& Goes, 2013). Like most studies, this study also had some limitations despite how well it was conducted and constructed. These limitations included the reduction of available participants from 140 to 70 because one company were not able to participate due to internal problems.

\section{The Instrument}

Measurements of the manufacturing leaders' trait emotional intelligence were achieved by using the Trait Emotional Intelligence Questionnaire, Short Form (TEIQUE-SF). The questionnaire consisted of 30 questions asking the participants for their degree of agreement ranking from completely disagree (1) to completely agree (7) (Petrides, 2017). Petrides developed the TEIQUE-SF in 2009 (Petrides, 2017). The topic of emotional intelligence has witnessed unprecedented developments in the past decades, and several schools of thought exist that focus on the accuracy of the measurements and its definitions (Benson et al., 2014). Despite arguments that there are separate personality traits from the cognitive ability attributes, leaders of the food and beverage manufactory industry must be measured on their personality traits or habitual patterns of behavior, thoughts, and emotions because of the coaching and relationship building they must exercise to succeed in their careers (Goleman et al. 2013; Petrides, 2017). Measurements from the trait EI methodology were necessary because they are consistent with the subjective nature of emotional experience. Trait EI measures were especially important as leaders in the manufacturing industry must use their judgment, problem-solving, and most importantly, decisionmaking skills to sense the hidden stress behind complacency behaviors. Leaders' personality traits measurements are important to organizations because they have higher internal consistency, more and better structural stability, and most importantly, their foundations are built on established psychometric and mathematical models (Petrides, 2017).

\section{Data Analysis}

In this study, SEM techniques were performed by utilizing Analysis of Moment Structures (AMOS) software to test a set of regression equations simultaneously and correlations. Two models were created based on the scope of the study determining the constructs. Data collection was done using the Trait Emotional Intelligence Questionnaire, Short Form, TEIQUE-SF (Petrides, 2017). After obtained the 
questionnaire results, answer values were entered into SEM application via SPSS data file. Results featured overall indexes of model fit, parameter estimates, standard errors, and test statistics for each parameter building Model 1. Model 2 tested the self-control and emotionality domains in all leaders. Hypotheses testing for this study were based on a 0.5 level of significance. Both models fit results tested the null and alternative hypotheses and tested their statistical significance including confirmatory factor analysis (CFA), ANOVA, correlation and descriptive estimates, and Chi-Square to find the difference in traits between the upper and middle leadership groups.

\section{Findings}

Two research questions led this quantitative correlational study to examine the relationship between the leaders of the food and beverage manufacturing industries emotional intelligence and their competency recognizing workers under stressful behavior. Leaders responded to identify workers under fatigue, complacency, and anxiety.

The first question examined five elements of the emotional intelligence domain known as well-being, self-control, emotionality, sociability, and independent facts, with the participation of all 70 leaders from 2 companies and depicted in Figure 2.

FIGURE 2 SEM MODEL 1

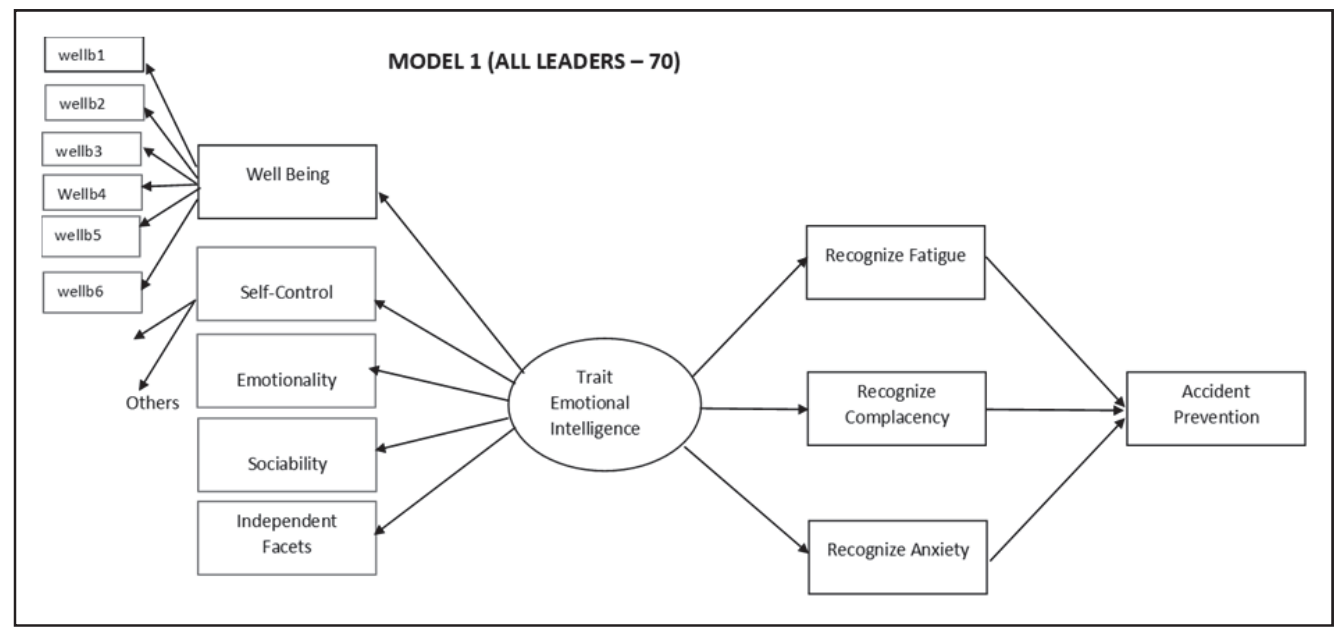

\section{MODEL 1: SEM CORRELATION ANALYSIS}

The construction of this model was the first step in using SEM to test the null hypotheses. Table 1 results suggested that the overall effect of emotional trait intelligence had estimates that showed a significant negative effect on IDs fatigue, complacency, and anxiety. However, these estimate results indicated that with an increase in emotional trait intelligence there would be a significant decrease in ID fatigue and ID complacency but not in ID anxiety (-1.306). These estimate results in Table 5 indicated that the correlation between ID fatigue and emotional trade has a $p$-value of .021 , which means that a $97.9 \%$ confidence interval would have its lower boundary at zero and may not be rejected. In other words, the probability of getting a critical ratio (CR) as large as -2.302 in absolute value is .021 . Therefore, the regression weight for Emotional Trait in the prediction of ID fatigue is significantly different from zero at the 0.05 level (two-tailed). Also, the correlation between ID complacency and emotional trade has an estimate of -.277 and a probability of getting a CR as large as -2.382 in absolute value has a $p$-value of .017. In other words, the regression weight for Emotional Trait in the prediction of ID complacency is also significantly different from zero at the 0.05 level (two-tailed) and may not be rejected as well. 
Finally, the probability of getting a critical ratio result as large as -1.306 in absolute value is .192 . The regression weight for Emotional-Trait in the prediction of ID_anxiety is not significantly different from zero at the 0.05 level (two-tailed). Therefore, the null hypothesis here should not be rejected while the null hypotheses were rejected for IDs fatigue and complacency. These results gave an almost correct model fit, but not the exact fit. The reason for the model to be acceptable is the no anticipation of reduced sample participants from 100 to 70. As denoted in Table 9, the root means a square error of approximation (RMSEA) is .093 indicated that the null hypothesis has a population no greater than 0.05 or $<.05$. The RMSEA values of 0.5 or less indicate a "close fit." It is assuming that this close fit result also supported the null hypotheses and rejected the alternative hypothesis HA2.

TABLE 1

FINAL MODEL REGRESSION WEIGHTS

\begin{tabular}{|l|l|l|c|c|c|c|}
\hline \multicolumn{1}{|c|}{ Variables } & & & Estimate & S.E. & C.R. & P \\
& & & & & & \\
\hline Wellbeing & $<-$ & Emotional Trait & .498 & .140 & 3.549 & $* * *$ \\
\hline emotional & $<-$ & Emotional Trait & 1.029 & .177 & 5.830 & $* * *$ \\
\hline self-control & $<-$ & Emotional Trait & 1.092 & .135 & 8.090 & $* * *$ \\
\hline independent facet & $<-$ & Emotional Trait & 1.241 & .171 & 7.250 & $* * *$ \\
\hline sociability & $<-$ & Emotional Trait & .400 & .138 & 2.896 & .004 \\
\hline wellbeing3 & $<-$ & wellbeing & 1.000 & & & \\
\hline wellbeing4 & $<-$ & wellbeing & .817 & .229 & 3.565 & $* * *$ \\
\hline wellbeing5 & $<-$ & wellbeing & .733 & .244 & 3.005 & .003 \\
\hline emotion2 & $<-$ & emotional & 1.000 & & & \\
\hline emotion3 & $<-$ & emotional & .889 & .195 & 4.564 & $* * *$ \\
\hline emotion4 & $<-$ & emotional & .637 & .156 & 4.076 & $* * *$ \\
\hline emotion8 & $<-$ & emotional & 1.011 & .202 & 5.006 & $* * *$ \\
\hline slfctrl1 & $<-$ & self-control & 1.000 & & & \\
\hline slfctr12 & $<-$ & self-control & .736 & .141 & 5.200 & $* * *$ \\
\hline slfctr14 & $<-$ & self-control & .356 & .101 & 3.531 & $* * *$ \\
\hline indepfac2 & $<-$ & independent facet & 1.000 & & & \\
\hline indepfac3 & $<-$ & independent facet & .887 & .146 & 6.074 & $* * *$ \\
\hline indepfac4 & $<-$ & independent facet & .266 & .121 & 2.188 & .029 \\
\hline social2 & $<-$ & sociability & 1.451 & .454 & 3.196 & .001 \\
\hline social4 & $<-$ & sociability & 1.149 & .358 & 3.206 & .001 \\
\hline social1 & $<-$ & sociability & 1.000 & & & \\
\hline wellb6 & $<-$ & Emollbeing & .758 & .212 & 3.580 & $* * *$ \\
\hline ID fatigue & -.274 & .119 & -2.302 & .021 \\
\hline ID complacency & - & -.277 & .116 & -2.382 & .017 \\
\hline ID anxiety & -.159 & .122 & -1.306 & .192 \\
\hline
\end{tabular}

*** The probability of getting critical ratios $>3.5$ in absolute values and less than 0.001 . Regression weights for traits in the prediction of the variables which are significantly different from zero at the 0.001 level (two-tailed). Approximately correct for large samples under suitable assumptions. 
The first model by SEM showed not a good fit. It was necessary to apply Confirmatory Factor Analysis to help the model fit of correlation, the final Model to answer question 1 was build using SEM. Correlations values are negative and are display under the column name Estimate. The final resultant model is below.

FIGURE 3

FINAL SEM MODEL 1

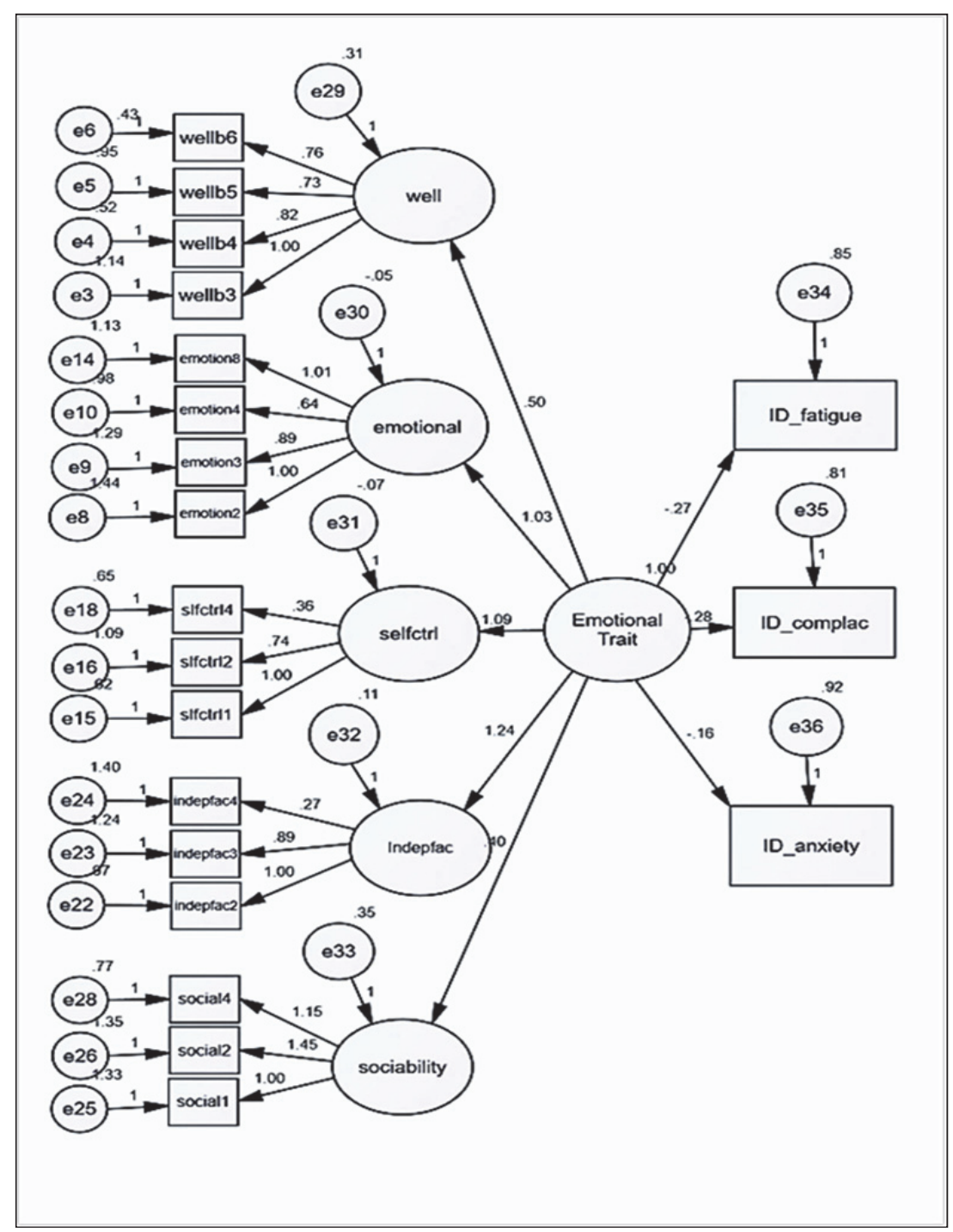

TABLE 2

MODEL 1 FIT SUMMARY (AFTER CFA)

\begin{tabular}{|c|c|c|c|c|c|c|}
\hline & CMIN/Df & GFI & CFI & TLI & RMSEA & RMR \\
\hline Ratio & 1.592 & 0.775 & 0.857 & 0.810 & 0.093 & 0.215 \\
\hline
\end{tabular}


As shown in Table 2, the final SEM for Model 1 have loadings less than 0.7. All the items having Standardized Regression Estimates less than 0.4 were deleted, two of well-being, four of emotionality, one from the independent fact, three from self-control, and 3 of from sociability. All groups preserved their minimum of 3 variables as require by SEM rules. The benefit of using CFA allowed me to determine whether items of the constructs aimed to measure those constructs well and with a minimum percent of error.

\section{MODEL 1 : MULTIPLE REGRESSION ANALYSIS}

TABLE 3

FATIGUE MODEL SUMMARY

\begin{tabular}{|c|c|c|c|}
\hline Multiple R & R Square & Adjusted R Square & Apparent Prediction Error \\
\hline .577 & .333 & .220 & .667 \\
\hline
\end{tabular}

In Table 3 the fatigue model has the same number of predictors as the complacency of Table 5 and the anxiety model of Table 7; however, the Adjusted R Squared .220 is higher than both. The adjusted Rsquared is a modified version of R-square that has been adjusted for the number of predictors in the model. The predictive R-squared .677 indicates how well a regression model predicts responses for new observations. This statistic results helped determine when the model fits the original data but is less capable of providing valid predictions for new observations. The benefit here is that help me avoid overfilling the model.

TABLE 4

CORRELATIONS AND TOLERANCE

\begin{tabular}{|l|c|c|c|c|c|c|}
\hline \multirow{2}{*}{ Competencies } & \multicolumn{3}{|c|}{ Correlations } & \multicolumn{2}{c|}{ Tolerance } \\
\cline { 2 - 4 } \cline { 6 - 7 } & $\begin{array}{c}\text { Zero- } \\
\text { Order }\end{array}$ & Partial & Part & \multirow{2}{*}{ Importance } & $\begin{array}{c}\text { After } \\
\text { Transformation }\end{array}$ & $\begin{array}{c}\text { Before } \\
\text { Transformation }\end{array}$ \\
\hline Well-Being & -.374 & -.272 & -.231 & .336 & .594 & .493 \\
\hline Self-Control & -.101 & .385 & .341 & -.151 & .466 & .371 \\
\hline Emotionality & -.382 & -.200 & -.167 & .263 & .528 & .446 \\
\hline Sociality & -.311 & -.146 & -.120 & .143 & .614 & .527 \\
\hline Independent-Facet & -.361 & -.314 & -.270 & .408 & .515 & .463 \\
\hline Dependent Variable: Fatigue
\end{tabular}

Some regression test required that there be a linear correlation between the dependent and independent variables. Correlation results are shown in Table 4 above indicating a poor correlation between construct results and recognition of the three models shown in Tables 4, 6, and 8 . Tolerance results indicate the improvements after the CFA model was complete. 
TABLE 5

COMPLACENCY MODEL SUMMARY

\begin{tabular}{|c|c|c|c|}
\hline Multiple R & R Square & Adjusted R Square & Apparent Prediction Error \\
\hline .522 & .272 & .149 & .728 \\
\hline
\end{tabular}

TABLE 6

CORRELATIONS AND TOLERANCE

\begin{tabular}{|l|c|c|c|c|c|c|}
\hline \multirow{2}{*}{ Competencies } & \multicolumn{3}{|c|}{ Correlations } & \multicolumn{2}{c|}{ Tolerance } \\
\cline { 2 - 3 } \cline { 6 - 7 } & $\begin{array}{c}\text { Zero- } \\
\text { Order }\end{array}$ & Partial & Part & Importance & $\begin{array}{c}\text { After } \\
\text { Transformation }\end{array}$ & $\begin{array}{c}\text { Before } \\
\text { Transformation }\end{array}$ \\
\hline Well-Being & -.272 & -.134 & -.115 & .154 & .555 & .493 \\
\hline Self-Control & -.290 & -.173 & -.150 & .248 & .412 & .371 \\
\hline Emotionality & -.194 & .168 & .145 & -.168 & .378 & .446 \\
\hline Sociability & .067 & .302 & .270 & .077 & .733 & .527 \\
\hline Independent-Facet &.- .408 & -.352 & -.320 & .689 & .484 & .463 \\
\hline
\end{tabular}

TABLE 7

ANXIETY MODEL SUMMARY

\begin{tabular}{|c|c|c|c|}
\hline Multiple R & R Square & Adjusted R Square & Apparent Prediction Error \\
\hline .481 & .231 & .130 & .769 \\
\hline \multicolumn{2}{|l}{} \\
Dependent Variable: Anxiety \\
Predictors: Well-Being Self-Control Emotionality Sociability Independent-Facet \\
\hline
\end{tabular}

TABLE 8

CORRELATIONS AND TOLERANCE

\begin{tabular}{|l|c|c|c|c|c|c|}
\hline \multirow{2}{*}{$\begin{array}{l}\text { Trait Emotional } \\
\text { Intelligence }\end{array}$} & \multicolumn{3}{|c|}{ Correlations } & \multicolumn{2}{c|}{ Tolerance } \\
\cline { 2 - 6 } \cline { 5 - 6 } $\begin{array}{c}\text { Zero- } \\
\text { Order }\end{array}$ & Partial & Part & Importance & $\begin{array}{c}\text { After } \\
\text { Transformation }\end{array}$ & $\begin{array}{c}\text { Before } \\
\text { Transformation }\end{array}$ \\
\hline Well-Being & -.324 & -.307 & -.283 & .468 & .715 & .493 \\
\hline Self-Control & -.320 & -.243 & -.220 & .540 & .318 & .371 \\
\hline Emotionality & -.211 & .145 & .129 & -.212 & .307 & .446 \\
\hline Sociability & -.255 & -.157 & -.139 & .186 & .686 & .527 \\
\hline Independent-Facet & .014 & .261 & .237 & .017 & .749 & .463 \\
\hline Dependent Variable: Anxiety
\end{tabular}




\section{MODEL 1: DESCRIPTIVE STATISTICS}

Data for Model 1 was collected from 70 participants who answer 30 questions, in a 7-point Likert scale surveying. The questions were six related to well-being, six questions to self-control, eight questions to emotionality, six to sociability, and four about independent See Table 9.

TABLE 9

MODEL 1- DESCRIPTIVE STATISTICS RESULTS

\begin{tabular}{|l|c|c|c|c|c|}
\hline \multicolumn{1}{|c|}{ Competencies } & $\mathrm{N}$ & Minimum & Maximum & Mean & Std. Deviation \\
\hline Well-Being & 70 & 4.50 & 7.00 & 6.0286 & .64454 \\
\hline Self-Control & 70 & 3.83 & 7.00 & 5.1976 & .75570 \\
\hline Emotionality & 70 & 3.50 & 7.00 & 5.2625 & .79404 \\
\hline Sociability & 70 & 3.33 & 7.00 & 5.2833 & .81371 \\
\hline Independent-Facet & 70 & 3.50 & 7.00 & 5.6714 & .89133 \\
\hline
\end{tabular}

FIGURE 4 HISTOGRAM WITH NORMAL DISTRIBUTION FOR ALL FIVE COMPETENCIES
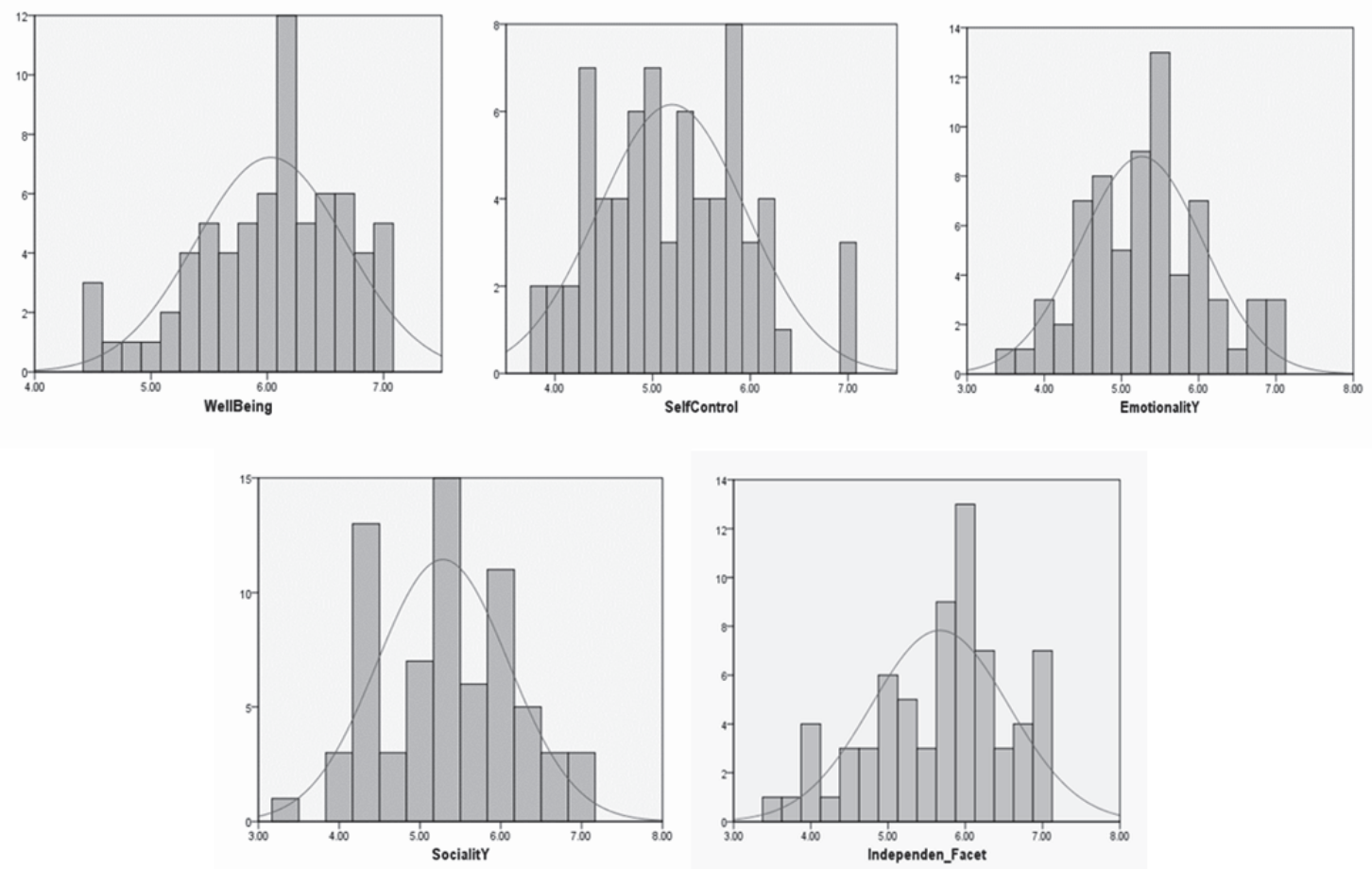

The mean scores of the EI statements were all above 6. Table 9 shows the mean scores slightly greater than 6.0 in all the well-being questionnaire results, suggesting that leaders agreed with all the statements that show optimism or higher self-steam than the other EI traits. The next significant score was self-control which shows a mean score of 5.19. This result suggests that leaders may have low control of their emotion becoming incapable of withstanding pressure and regulating stress on others. Emotionality 5.26 and Sociability 5.28 mean scores suggest that the leaders are somehow ineffective in recognizing their workers' feelings and have poor social skills. Independent facets mean result was 5.67. The result 
was the second larger mean value indicating that they are flexible in adapting to new conditions and somehow driven to defeat adversity.

The second question has two elements of the emotional intelligence domain known as with the participation of all participants and with 13 upper leader's participants and 57 middle leader's participants from both companies. Self-control and Emotionality are depicted in Figure 5.

\section{FIGURE 5 \\ SEM MODEL 2}

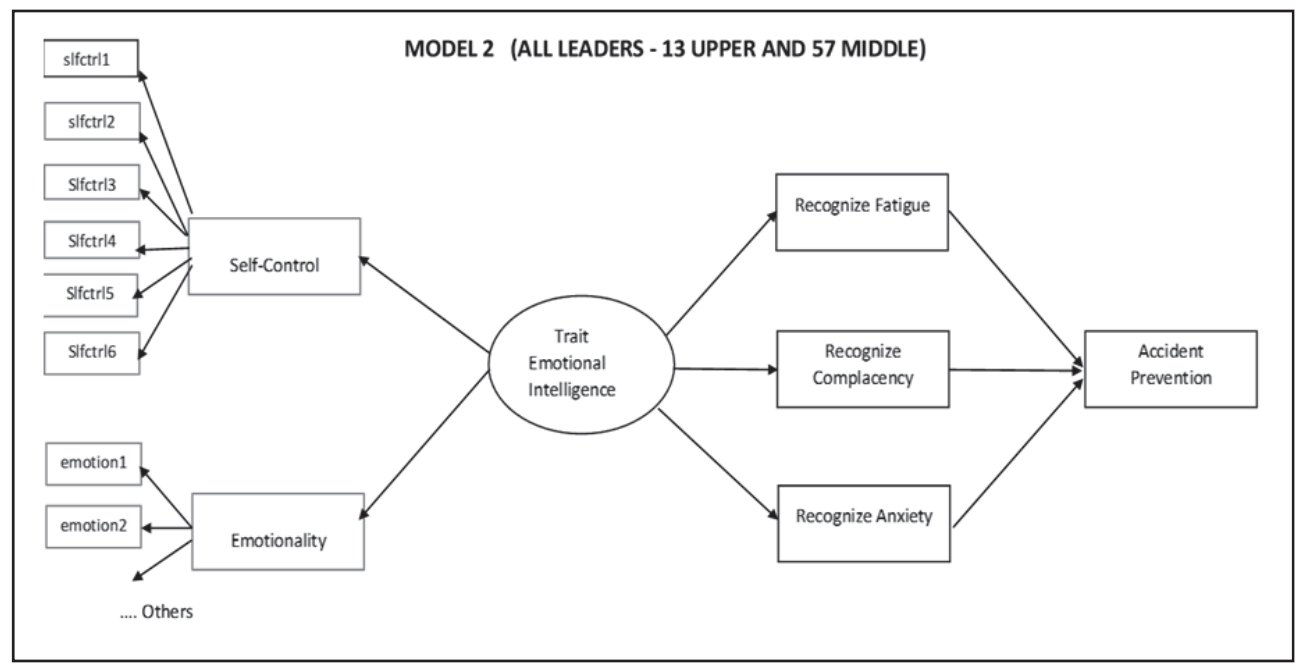

The models were tested for goodness-of-fit to ensure it was well specified to estimate the relationships hypothesized using SEM. Goodness-of-fit indices are in Table 6.

\section{MODEL 2: SEM CORRELATION ANALYSIS}

The relationship among variables was tested via SEM modeling. Model 2 showed regression weights that suggest that self-control and emotionality dimensions of emotional intelligence have negative estimates on fatigue, complacency and anxiety identification. The construction of this second model was also the first step in using SEM to test the null hypotheses. Therefore, Table 10 shown fatigue as the probability of getting a critical ratio as large as -.321 in absolute value is $p=.748$. The regression weight for Emotional-Trait in the prediction of ID fatigue is not significantly different from zero at the 0.05 level (two-tailed) and should not be rejected; complacency estimate shows the probability of getting a critical ratio as large as -.155 and an absolute value of $p=.877$. Here, the regression weight for Emotional Trait in the prediction of ID complacency is also not significantly different from zero at the 0.05 level (two-tailed) and also should not be rejected.

TABLE 10

MODEL 2 REGRESSION WEIGHTS

\begin{tabular}{|l|l|l|c|c|c|c|}
\hline \multicolumn{1}{|c|}{ Variables } & & & Estimate & S.E. & C.R. & P \\
\hline ID fatigue & $<-$ & Emotional Trait & -.151 & .471 & -.321 & .748 \\
\hline ID complacency & $<-$ & Emotional Trait & -.071 & .461 & -.155 & .877 \\
\hline ID anxiety & $<-$ & Emotional Trait & -.264 & .431 & -.613 & .540 \\
\hline
\end{tabular}


Finally, the probability of getting a critical ratio as large as -.613 and an absolute value of $p=.540$ for Emotional Trait in the prediction of ID anxiety is not significantly different from zero at the 0.05 level (two-tailed) and should not be rejected as well. The $p$-value shows a value greater than 0.05 suggesting that there is no effect of emotional traits in the leadership groups failing to predict identification of anxiety. Results from the data analysis suggested that the null hypothesis of research question 2 should be accepted and the alternative hypothesis rejected. Consequently, the food and beverage manufactory leaders do not execute emotional perceptions or controls to prevent employees' underlying complacent stress behavior. Table 10 results displayed negative regression weights suggesting that emotional traits had a negative impact on ID fatigue, ID complacency, and ID anxiety.

\section{CONSTRUCT VALIDITY}

In testing the leaders in both traits, separation of the middle leadership group from the upper leadership group was done to understand if there was a difference between the leaders that lead personally during daily operations versus the ones that have less participation in operations. The data were first analyzed using confirmatory factor analysis (CFA) to make sure the model will fit in SEM and to be able to test the hypotheses 2 .

TABLE 11

STANDARDIZED REGRESSION WEIGHTS

\begin{tabular}{|c|c|c|c|c|}
\hline Variable & $\begin{array}{l}\text { Standardized } \\
\text { Estimate }\end{array}$ & P-Value & $\begin{array}{l}\text { Average Variance } \\
\text { Extracted (AVE) }\end{array}$ & $\begin{array}{c}\text { Composite } \\
\text { Reliability } \\
\text { (CR) }\end{array}$ \\
\hline Emotion $1<-$ Emotionality & 0.219 & Regressed & \multirow{8}{*}{0.248} & \multirow{8}{*}{0.689} \\
\hline Emotion $2<$ - Emotionality & 0.675 & 0.094 & & \\
\hline Emotion3 <- Emotionality & 0.639 & 0.096 & & \\
\hline Emotion $4<-$ Emotionality & 0.562 & 0.101 & & \\
\hline Emotion5 <- Emotionality & 0.415 & 0.121 & & \\
\hline Emotion6 <- Emotionality & 0.368 & 0.133 & & \\
\hline Emotion $7<-$ Emotionality & 0.107 & 0.454 & & \\
\hline Emotion $8<$ - Emotionality & 0.663 & 0.094 & & \\
\hline Selfcontrol1 <- Self-control & 0.811 & Regressed & \multirow{6}{*}{0.263} & \multirow{6}{*}{0.644} \\
\hline Selfcontrol $2<$ - Self-control & 0.618 & $<0.001$ & & \\
\hline Selfcontrol3 <- Self-control & 0.341 & 0.07 & & \\
\hline Selfcontrol4 <- Self-control & 0.502 & $<0.001$ & & \\
\hline Selfcontrol5 <- Self-control & 0.363 & 0.004 & & \\
\hline Selfcontrol6 <- Self-control & 0.193 & 0.136 & & \\
\hline
\end{tabular}

The components were further examined for construct reliability (CR) and convergence validity. Convergence validity was measured by computing the average variance extracted (AVE). It was hypothesized that the leaders of the food and beverage manufacturing industries execute or do not execute emotional perceptions and control to prevent employees' underlying complacent stress behavior — results displayed in Table 11 above. 
FIGURE 6

FINAL SEM MODEL 2

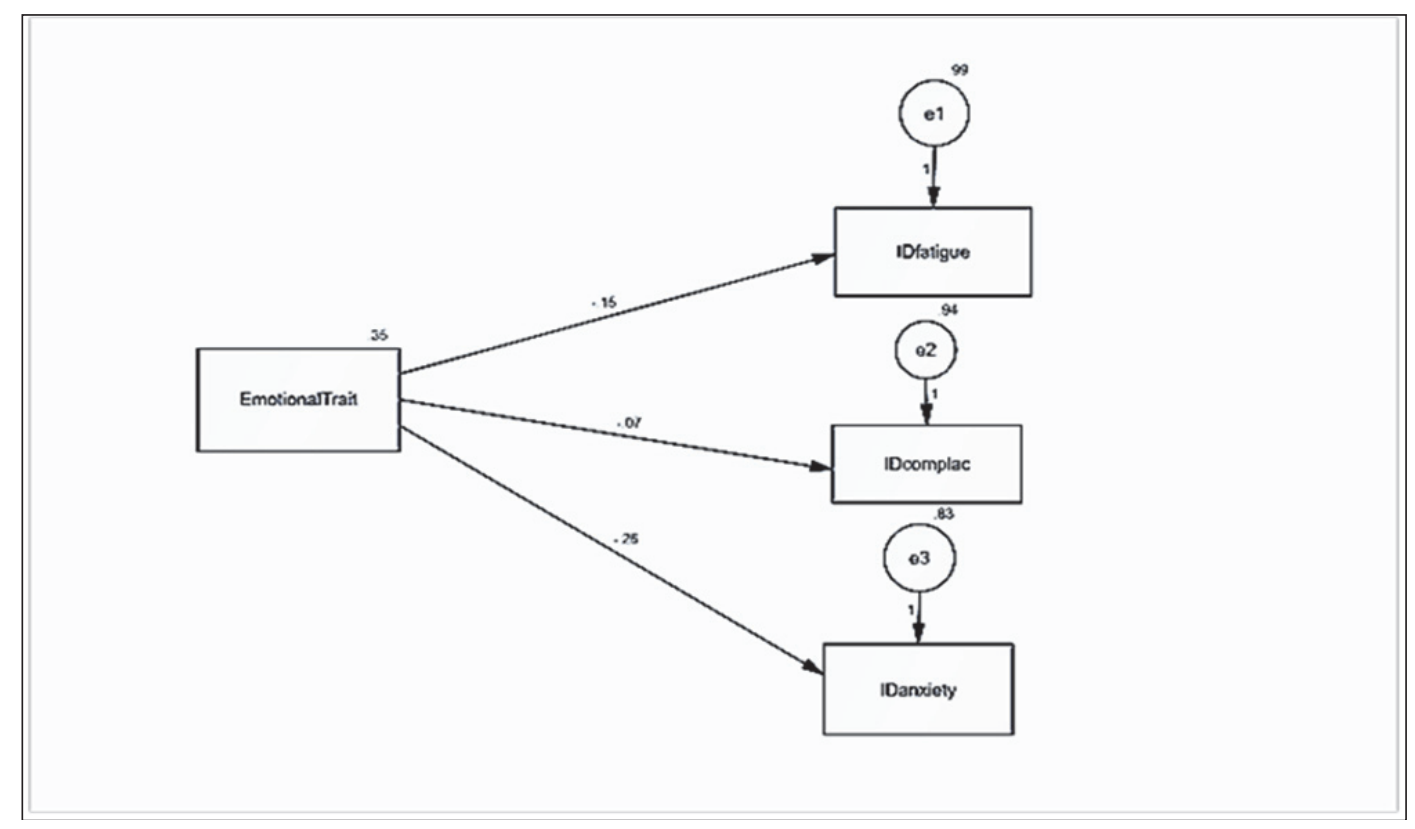

MODEL 2 : MULTIPLE REGRESSION ANALYSIS

TABLE 12

FATIGUE CORRELATIONS AND TOLERANCE

\begin{tabular}{|c|c|c|c|c|c|c|}
\hline \multirow{2}{*}{} & \multicolumn{3}{|c|}{ Correlations } & \multicolumn{2}{c|}{ Tolerance } \\
\cline { 2 - 3 } \cline { 5 - 6 } & $\begin{array}{c}\text { Zero- } \\
\text { Order }\end{array}$ & Partial & Part & Importance & $\begin{array}{c}\text { After } \\
\text { Transformation }\end{array}$ & $\begin{array}{c}\text { Before } \\
\text { Transformation }\end{array}$ \\
\hline Self-Control & -.106 & .135 & .124 & -.094 & .707 & .533 \\
\hline Emotionality & -.389 & -.397 & -.394 & 1.094 & .707 & .533 \\
\hline
\end{tabular}

TABLE 13

COMPLACENCY CORRELATIONS AND TOLERANCE

\begin{tabular}{|c|c|c|c|c|c|c|}
\hline \multirow{2}{*}{} & \multicolumn{3}{|c|}{ Correlations } & \multicolumn{2}{c|}{ Tolerance } \\
\cline { 2 - 3 } \cline { 6 - 6 } & $\begin{array}{c}\text { Zero- } \\
\text { Order }\end{array}$ & Partial & Part & Importance & $\begin{array}{c}\text { After } \\
\text { Transformation }\end{array}$ & $\begin{array}{c}\text { Before } \\
\text { Transformation }\end{array}$ \\
\hline Self-Control & -.288 & -.246 & -.236 & .524 & .957 & .533 \\
\hline Emotionality & -.277 & -.232 & -.223 & .476 & .957 & .533 \\
\hline Dependent Variable: Identify Complacency
\end{tabular}


TABLE 14

ANXIETY CORRELATIONS AND TOLERANCE

\begin{tabular}{|c|c|c|c|c|c|c|}
\hline \multirow{2}{*}{ Competencies } & \multicolumn{3}{|c|}{ Correlations } & \multicolumn{2}{|c|}{ Tolerance } \\
\cline { 2 - 4 } \cline { 5 - 6 } & $\begin{array}{c}\text { Zero- } \\
\text { Order }\end{array}$ & Partial & Part & \multirow{2}{*}{ Importance } & $\begin{array}{c}\text { After } \\
\text { Transformation }\end{array}$ & $\begin{array}{c}\text { Before } \\
\text { Transformation }\end{array}$ \\
\hline Self-Control & -.355 & -.311 & -.305 & 1.189 & .465 & .533 \\
\hline Emotionality & -.200 & .093 & .087 & -.190 & .465 & .533 \\
\hline Dependent Variable: Identify Anxiety
\end{tabular}

\section{MODEL 2: DESCRIPTIVE STATISTICS}

Descriptive Statistics for Model 2 are presented in Table 15. This model consisted of two constructs named emotional perceptions and controls to prevent employees' underlying complacent stress behavior. Data consisted of all 70 participants responding to 14 questions, 8 in emotionality and 6 in self-control. Descriptive statistics during the development of Model 2 suggested mean values slightly above 5.0 in the questionnaire results. As shown in Table 15 self-control construct shows a mean of 5.19 and an emotionality construct mean of 5.26. Normal distribution graphs indicate that the majority of the respondents' perceptions concentrate in the lower self-control statements indicating the low capability to control their emotions and missing the opportunity to manage stress in others. The respondents' emotionality construct shows a better distribution indicating a better chance to understand their own and others' feelings and a chance to create relationships perhaps but not to a greater extent. Model 2 questions were designed to test their emotional impulse control and stress management. Normal distribution of selfcontrol and emotionality are shown in Figure 7.

TABLE 15

MODEL 2- DESCRIPTIVE STATISTICS RESULTS

\begin{tabular}{|l|c|c|c|c|c|}
\hline \multicolumn{1}{|c|}{ Competencies } & $\mathrm{N}$ & Minimum & Maximum & Mean & Std. Deviation \\
\hline Self-Control & 70 & 3.83 & 7.00 & 5.1976 & .75570 \\
\hline Emotionality & 70 & 3.50 & 7.00 & 5.2625 & .79404 \\
\hline
\end{tabular}

FIGURE 7

HISTOGRAM NORMAL DISTRIBUTION OF SELF-CONTROL AND EMOTIONALITY
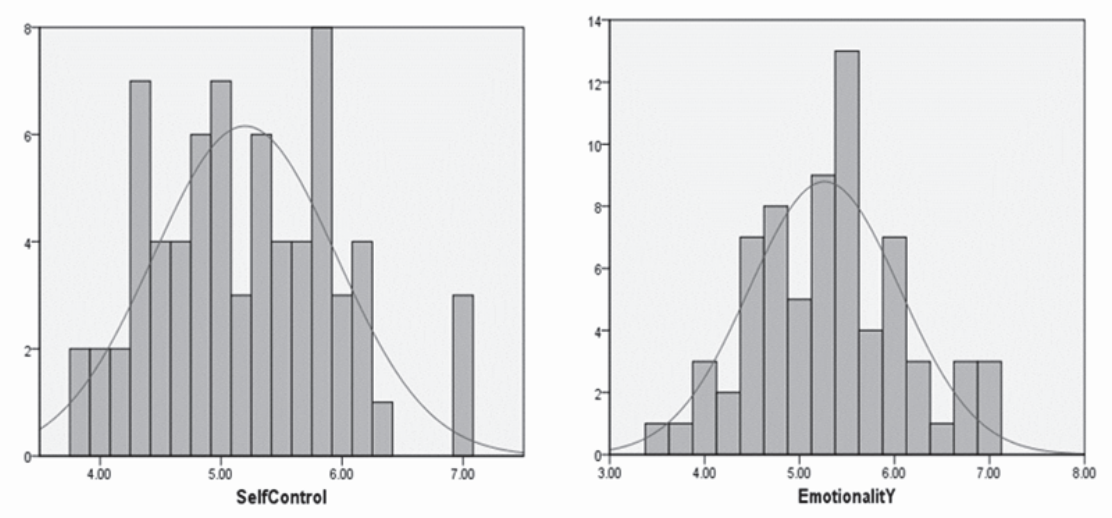


\section{CHI-SQUARE MULTIGROUP ANALYSIS}

Chi-Square tests were applied to the final weights; the model suggests that there is no significant difference between the groups in predicting the specify paths, concluding that the emotional traits of selfcontrol and emotionality are similar in both groups when predicting fatigue, complacency, and most important anxiety.

TABLE 15

ANXIETY RECOGNITION DIFFERENCE BETWEEN UPPER \& MIDDLE GROUPS

\begin{tabular}{|l|l|l|l|l|l|l|l|}
\hline Model & DF & CMIN & P & $\begin{array}{l}\text { NFI } \\
\text { Delta-1 }\end{array}$ & $\begin{array}{l}\text { IFI } \\
\text { Delta-2 }\end{array}$ & $\begin{array}{l}\text { RFI } \\
\text { rho-1 }\end{array}$ & $\begin{array}{l}\text { TLI } \\
\text { rho2 }\end{array}$ \\
\hline Structural weights & 1 & .113 & .380 & .003 & .003 & -.213 & -.294 \\
\hline
\end{tabular}

After constraining the path from emotional trait to ID anxiety the $p$-value in Table 15 show to be greater than $0.05(p=.380)$, indicating that there is no significant difference between upper and middle leadership groups in predicting the anxiety path. Thus, emotional traits of emotionality and self-control for the upper and middle leadership groups are not different predicting anxiety.

\section{FINAL THOUGHTS}

SEM is a largely confirmatory, rather than exploratory technique which is used in this study to determine if the models fit rather than suitable (Sideridis et al., 2014). A good-fitting model is one that is reasonably consistent with the data. The major reason for computing a fit index is that chi-square needs to show if it is statistically significant (Sideridis et al., 2014). Thus, the main findings of the study were as follows:

- All dimensions of Emotional Intelligence had a significant impact on the leaders Emotional Intelligence traits.

- Emotional Intelligence traits results showed how leaders' competencies might impact the recognition of fatigue, complacency, and anxiety.

- As emotional trait intelligence increased, there was a significant decrease in fatigue and complacency but not in anxiety.

- Results of all leadership groups surveying demonstrated that leaders' ability to recognize anxiety or stress behavior is not being exercised.

- The leaders' answers on self-control and emotionality dimensions had a negative effect on fatigue, complacency and anxiety identification.

- There was no significant difference between upper and middle leadership groups in predicting the specified path. Both groups are found not to be able to predict anxiety behavior.

The findings of this correlational study on leaders of the food and beverage manufacturing industries emotional traits were presented. The results to derive unbiased estimates for the relations between latent constructs were also presented. SEM modeling was divided into two parts, the measurement model in where it related the measured variables to the latent variables, and the structural model where latent variables relate to one another. Statistically, the models were evaluated by comparing two variancecovariance matrices. SEM was used to analyze the observed variables of fatigue, complacency, and anxiety with a more restrictive set of assumptions than CFA because it assumed that all variables were measured without errors while SEM used the latent variables to count for measurement error. Chi-Square tests found no difference between the middle and upper leadership groups recognizing fatigue, complacency, or anxiety to help to prevent accidents. 


\section{DISCUSSION}

Two conceptual frameworks were analyzed using structural equation models to understand the patterns of correlation/covariance among a set of variables and to help explain as much of their variance as possible with the model specified. Traditional statistical methods normally utilize one statistical test to determine the significance of the analysis. However, structural equation modeling relies on several statistical tests to determine the adequacy of model fit to the data. Although the absence of one organization reduced the participant's size, CFA adjustments to model fit gave SEM acceptable results to test the hypothesis. The size adjustments had no impact on the final models' results. The findings confirmed the significant impact that emotional intelligence traits in members of the food and beverage manufacturing industries exist but in a small scale and the overall effect of emotional trait intelligence had a poor significant effect on the identification of fatigue, complacency, and especially anxiety (p-value < $0.005)$.

Ratio analysis was executed to determine model fit. As depicted in Table 2, the incremental measure of fit name the Comparative Fit Index (CFI) and the incremental index of the fit name the Tucker-Lewis index (TLI) depend on the average size of the correlations in the data. If the average correlation between variables is not high, then the TLI will not be very high. Thus, if the dataset has weak correlations, such was the case here, an incremental fit index may not be very informative. The rule of thumb then led me to examine the Root-Mean-Square Error of Approximation (RMSEA) as a supplementary statistic to determine fit. Results indicated that an increase in emotional intelligence trait values might significantly decrease identifying fatigue and complacency but no in anxiety. Adjustments from the original model suggest that all leaders of the food and beverage manufactories EI traits have a weak impact on accidental preventions and may not be able to recognize workers under stress behavior. Safety performance in a workplace can reach a point where it levels out becoming an unsustainable performance plateau which prevents leaders from carrying on their work to the next level (Colm, 2014). The familiarization with the everyday work process makes workers take unnecessary risks. Soon after that, workers begin bending procedures and rules and begin taking shortcuts as they become complacent until a safety error happens ( $\mathrm{Lu} \& \mathrm{Kuo}, 2016)$. From our literature review, we learned that one of the major setbacks for workers is the misuse of their expertise and knowledge, becoming complacent and capable of hiding their anxieties and fatigues.

The recognition of complacency is of importance for leaders to identify workers short-cuts, unsafe behaviors, and prevent injuries before a fatality occurs. The first results of this SEM model indicated during path analysis a weak model fit. Standardized Regression Weights suggested that the factor loadings were mostly less than 0.7 giving a lower average variance extracted (AVE) with a threshold of 0.5. Although this is a standard CFA practice, the questions removed with low weight values indicated the absence of emotional traits which can help identify stress or anxiety. Finally, SEM Model 1 fit was acceptable after the confirmatory factor analysis (CFA) took place. These results indicated that only $43 \%$ of trait answers showed acceptable correlation. The results indicated poor significance in the prevention of safety errors in leaders of both companies.

With SEM Model 2, Table 15 descriptive statistics results showed means and standard deviations close values. These close results could be an indication of similarities in the answer patterns of both groups' emotionality and self-control traits. Although descriptive statistic results indicated no much differences between both groups' trait deviations, the results indicated no significance p-values in neither group. It was not until the CFA was run to showed poor values of CFI, GFI, and TLI indicating poor model fit. Thus, deletions of questions took place to make the model fit the data in question. This failure could be attributed to several circumstances. First, we learned from our literature review that historically, complacent workers are the product of complacent leaders (Pater, 2014) which may be incapable of increasing their level of self-emotion to become clear about their own and other peoples' feelings, thus, incapable of creating a relationship with their workers. Second, the equal amount of self-emotional control indicated that either group might not be capable of withstanding pressure to regulate their own or other's stress. Third, neither group may be capable of communicating their feelings to others failing to 
identify other peoples' feelings. The poor relationship results suggested that both leadership groups (upper and middle) self-control and emotionality have the same impact on accidental preventions concluding that leaders from both groups may not be able to recognize workers under stress or anxiety behavior as well. Model 2 SEM showed a moderately acceptable fit. The results indicated that all the leaders had poor significance in the prevention of safety errors in both groups.

As we learned from expectancy theory, leaders' motivational levels are determining by the relationship between their efforts and their performances, their relationship between performances and rewards of their work outcomes, and their relationship between the rewards of their work results and their personal goals (Lazaroiu, 2015). According to Ernst (2014), expectancy is "a person's perception of the probability that effort will lead to successful performance" (Ernst, 2014, p. 538). In our study, expectancy is our leaders' beliefs that if they put forth efforts to recognize complacent stress behavior from their employees, they can successfully prevent accidents in the workplace. The leader's results indicate that there may be a very low motivational factor at both levels of management. These results could be an indication of an uncertain economy or the current conditions of these companies demand and supply issues. The Chi-Square testing proved that there were no differences in the power of leadership selfmastery skills (Hamzah, Othman, Rashid, Besir, \& Hashim, 2012). This test demonstrated about the same level of mindset in both groups when making decisions to prevent implicit complacent behavior due to stress (Hamzah et al., 2012; Naderpour, Lu, \& Zhang, 2014).

\section{CONCLUSION}

The purpose of this quantitative correlational study was to examine if the leaders of the food and beverage manufactory had the proper emotional intelligence traits to recognize employees' underlying complacent stress behavior. CFA analysis and sample size adjustments had no impacts on the final models' results. After final SEM models achieved a reasonable fit, hypothesis test took place and found disappointing results. These results indicated that the leaders of the food and beverage manufacturing do not have the appropriate emotional measures which are significant to recognize employees' underlying complacent behavior. Also, provided standardized regression weights with paths showing different results for upper and middle leadership groups. Thus, concluding that the EI for both upper and middle leadership groups have the same impact on accidental preventions. These findings may be of great significance to the food and beverage manufacturing industries where injuries and fatality errors continue to be high. Hidden fatigue, stress, and complacent behaviors continue to add injuries and fatalities to the American workforce and impacting our society. Consequently, by adopting emotional intelligence competencies, the leaders of the food and beverage manufacturing industries may positively impact the safety awareness in their respective organizations and help in the reduction of safety injuries and fatalities in their workplaces and communities.

\section{REFERENCES}

Ackley, D. (2016). Emotional intelligence: A practical review of models, measures, and applications. Consulting Psychology Journal: Practice and Research, 68(4), 269-286. doi:10.1037/cpb0000070

Adhikari, P. (2015). Errors and accidents in the workplace. Sigurnost, 57(2), 127-137. Retrieve from http://hrcak.srce.hr/file/206833

Arstad, I. \& Aven, T. (2017). Managing major accident risk: Concerns about complacency and complexity in practice. Elsevier Ltd., 91, 114-121.

doi:10.1016/j.ssci.2016.08.004

Arthur Jr., W., Glaze, R., Jarrett, S., White, C., Schurig, I., \& Taylor, J. (2014).Comparative evaluation of three situational judgment test response formats in terms of construct-related validity, subgroup differences, and susceptibility to respond to distortion. American Psychological Association, 99(3), 535-545. doi:10.1037/a0035788. 
Benson, R., Fearon, C., McLaughlin, H., \& Garratt, S. (2013). Investigating trait emotional intelligence among school leaders: Demonstrating a useful self-Assessment approach. School Leadership \& Management, 34(2), 201-222. doi:10.1080/13632434.2013.813450

Colm, M. (2014). Breaking through the plateau. The Safety and Health Practitioner Safety Performance, 32(6), 51-69. Retrieved from www.shponline.co.uk/features/features/full/breaking-through-theplateau

Daher, N. (2015). Emotional and cultural intelligence as an assessment tool for recruiting, selecting and training individual candidates. International Journal of Business and Public Administration, 12(1), 167-180.

Eberly, M., Johnson, M., Hernandez, M., \& Avolio, B. (2013). An integrative process model of leadership: Examining loci, mechanisms, and events cycles. American Psychologist Association, 68(6), 427-443. DOI: 10.1037/a0032244.

Ernst, D. (2014). Expectancy theory outcomes and student evaluations of teaching, educational research and evaluation. Taylor \& Francis Publishing Online, 20(7-8), 536-556. DOI: 10.1080/13803611.2014.997138. DOI from http://dx.doi.org/10.1080/13803611.2014.997138

Farh, C. I., Seo, M. G., \& Tesluk, P. E. (2012). Emotional intelligence, teamwork effectiveness and job performance: The moderating role of job context. Journal of Applied Psychology, 97(4), 890-900. doi: $10.1037 / \mathrm{a} 0027377$

Fischer, T., Dietz, J., \& Antonakis, J. (2016). Leadership process models: A review and synthesis. Research Gate Publication. DOI: 10.1177/0149206316682830.

Goleman, D., Boyatzis, R., \& McKee, A. (2013). Primal Leadership: Unleashing the power of emotional intelligence. Harvard Business School Publishing, Cambridge, MA

Hallett, M., \& Hoffman, B. (2014). Performing under pressure: Cultivating the peak performance mindset for workplace excellence. American Psychological Association, 66(3), 212-230. doi: $10.1037 / \mathrm{cpb} 0000009$

Hamm, M., Klassen, T., Scott, S., Moher, D. \& Hartling, L. (2013). Education in health research methodology: Use of a wiki for knowledge translation. PLOS ONE, 8(5), 1-7. DOI: 10.1371/journal.pone.0064922

Hamzah, M., Othman, A., Rashid, M., Besir, M., \& Hashim, N. (2012). Examining the predictive power of leadership competency dimensionality in higher education institutions. Social and Behavioral Science, Elsevier, 65, 1000-1006. doi: 10.1016/j.sbspro.2012.11.233

Humphrey, R. (2012). How do leaders use emotional labor? Journal of Organizational Behavior, 33, 740744. DOI: $10.1002 /$ job.1791

Ismail, F., Hashim, A., Wan Ismail, W., Kamarudin, H. \& Baharom, Z. (2012). Behavior-based approach to quality and safe environment improvement: Malaysian experience in the oil and gas industry. Elsevier Published Ltd, 35, 586-594. doi: 10.1016/j.sbspro.2012.02.125

Ismail, A., Nor, S., Yahya, Z., Ismail, Y. \& Samah, A. (2013). Social support in job performance as an antecedent of work intrusion on family conflict: Empirical evidence. Journal of Contemporary Management Issues, 18(2), 37-55. Retrieved from http://search.proquest.com.contentproxy.phoenix.edu/sharedreferences/MSTAR_1476270833/63 F653628BAC4392PQ/1?accountid=35812.

Jadhav, T., \& Gupta, S. K. (2014). Global communication skills and its relationship with emotional intelligence. American Journal of Management, 14(4), 82-88. Retrieved from $\mathrm{http} / / /$ search.proquest.com.ezp.waldenulibrary.org/docview/1648606623?accountid=14872.

Joost, E. (2013). Minimizing human errors in the workplace. Willis North America's Specialty Practices. Retrieved from http://www.resilience.willis.com/articles/2013/09/23/human-errors-workplace/

Khan, H., \& Bashar (2016). Does globalization create a level playing field through outsourcing and brain drain in the global economy? The Journal of Developing Areas, 50(6), 190-207. DOI: $10.1353 /$ jda.2016.0143

Kumar, S., Dhingra, A. K., \& Singh, B. (2017). Implementation of the lean-kaizen approach in fastener industries using the data envelopment analysis. FACTA UNIVERSITATIS, 15(1), 145-161. DOI: 10.22190/FUME161228007K. 
Lazaroiu, G. (2015). Work motivation and organizational behavior. Contemporary readings in law and social justice. Addleton Academic Publishers, 7(2), 65-75, Retrieved from

https://www.scribd.com/document/294852320/Employee-Motivation-and-Job-Performance

Lu, C. \& Kuo, S. (2016). The effect of job stress on self-reported safety behavior in container terminal operations: The moderating role of emotional intelligence. Elsevier, 37, 10-26. Retrieved from http://doi.org/10.1016/j.trf.2015.12.008.

Malos, R. (2012). The most important leadership theories. Annals of Eftimie Murgu University Resita, Fascicle II, Economic Studies, 413-420.

Mathew, M., \& Gupta, K (2013). Transformational leadership: emotional intelligence. SCMS Journal of Indian Management, 12(2), 75-89.

McCleskey, J. (2014). Situational, transformational, and Transactional leadership and leadership development. Journal of Business Studies Quarterly, 5(4), 117-130.

Miao, C., Humphrey, R. \& Qian, S. (2016). Leader emotional intelligence and subordinate job satisfaction: A meta-analysis of main, mediator, and moderator effects. Elsevier Ltd., 102, 13-24. doi: 10.1016/j.paid.2016.06.056

Naderpour, M., Lu, J., \& Zhang, G. (2014). An intelligent situation awareness support system for safetycritical environments. Decision Support System, 59, 325-340.

Newton, C., Teo, S., Pick, D., Ho, M., \& Thomas, D. (2015). Emotional intelligence as a buffer of occupational stress. Emerald Insight Personnel Review, 45(5), 1010-1028. DOI from http://dx.doi.org/10.1108/PR-11-2014-0271.

Nohe, C., Meier, L., Sonntag, K., \& Michel, A. (2015). The chicken or the egg? A metanalysis of panel studies of the relationship between work-family conflict and strain. Journal of Applied Psychology, 100(2), 522-536. DOI from http://dx.doi.org/10.1037/a0038012.

Parijat, P., \& Bagga, S. (2014). Victor Vroom's expectancy theory of motivation - An evaluation. Global Wisdom Research Publications, 9, 1-8.

Pater, R. (2014). Overcoming the top 10 leadership mistakes. Change your game to achieve gamechanging results. Professional Safety, 59(6), 30-32.

Petrides, K.V. (2017). Intelligence, emotional. Reference Module in Neuroscience and Biobehavioral Psychology. University College, London. DOI from http://dx.doi.org/10.1016/B978-0-12-8093245.05601-7.

Sideridis, G., Simos, P., Papanicolaou, A., \& Fletcher, J. (2014). Using structural equation modeling to assess functional connectivity in the brain: Power and sample size considerations. Educational and Psychological Measurement, 74(5) 733-758. DOI: 10.1177/0013164414525397.

Simon, K., \& Goes, J. (2013). Dissertation \& scholarly research: Recipes for success. Dissertation Success LLC. 2013 Edition.

Strutton, D., \& Tran, G. (2014). How to convert bad stress into good. Emerald Group Publishing Limited. Management Research Review, 37(12), 1093-1109. DOI 10.1108/MRR-06-2013-0139

Sunindijo, R. \& Zou, P. (2013). The roles of emotional intelligence, interpersonal skills, and transformational leadership on improving construction safety. Australasian Journal of Construction Economics and Building, 13(3), 97-113.

DOI: 10.5130/AJCEB.v13i3.3300.

United States Department of Labor (2015). Census of fatal occupational injuries. CFOI. Retrieved from https://www.bls.gov/iif/oshcfoil.htm\#2015

Wells Jr., J. (2015). Building a progressive safety culture. Five crucial tenets. Professional Safety. Leading Thoughts, 60(7), 22-23.

Wolf, E., Harrington, M., Clark, S., \& Miller, M. (2013). Sample size requirements for structural equation models: An evaluation of power, bias, and solution propriety. Educational and Psychological Measurement, 73(6), 913-934.

DOI: 10.1177/0013164413495237.73(6) 913-934

Yang, D., Rosenblau, G., Keifer, C., \& Pelphrey, K. (2015). An integrative neural model of social perception, action observation, and theory of mind. Neuroscience and Biobehavioral Reviews, 51, 263-275. DOI at http://dx.doi.org/10.1016/j.neubiorev.2015.01.020

104 Journal of Organizational Psychology Vol. 19(5) 2019 